Journal homepage: http://www.journalijar.com
Journal DOI: $10.21474 /$ IJAR01

RESEARCH ARTICLE
INTERNATIONAL JOURNAL

OF ADVANCED RESEARCH

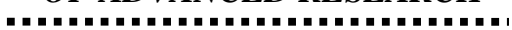

\title{
A COMPARATIVE STUDY OF SERUM $\beta$ HCG CONCENTRATION AND LIPID PROFILE IN PREGNANCY INDUCED HYPERTENSIVE AND NORMOTENSIVE WOMEN IN THIRD TRIMESTER OF PREGNANCY.
}

Jadab Kishore Phukan' ${ }^{1}$ and Tapas Paul ${ }^{2}$.

1. Senior Resident Doctor, Deptt. of Biochemistry, LGB Regional Institute of Mental Health, Tezpur, Assam.

2. Medical \& Health Officer, Karimganja Civil Hospital, Karimganja, Assam.

\section{Manuscript Info}

Manuscript History:

Received: 18 May 2016

Final Accepted: 29 June 2016

Published Online: July 2016

Key words:

Human chorionic gonadotropin, pregnancy induced hypertension, pre-eclamsia, eclamsia.

*Corresponding Author

Jadab Kishore Phukan.

\begin{abstract}
Hypertensive disorders are among the commonest and unpredictable medical disorders during pregnancy contributing significantly high to maternal and perinatal morbidity and mortality. Human chorionic gonadotropin (hCG) is a glycoprotein that is produced during pregnancy by the developing embryo and later by the syncytio trophoblast of the placenta mainly. Serum $\beta$ hCG is found to be abnormally raised in the urine and serum of pregnant women with pregnancy induced hypertension. The aim of the study was to evaluate the concentration of serum $\beta$ hCG and lipid profile level and its correlation with pregnancy induced hypertension. To compare the serum $\beta \mathrm{hCG}$ and lipid profile level between study and control group. The study was carried out in the department of Biochemistry, Assam Medical College and Hospital, Dibrugarh. The study includes two group cases and controls. The cases included in the study were taken from Obstetrics and Gynaecology Department, Assam Medical College \& Hospital during the period of study. The cases comprised of 50 clinically established cases of Pregnancy Induced Hypertension (PIH) in their third trimester and the control group comprised of 50 cases of normotensive pregnant patients in the third trimester. The differences of mean serum $\beta$ hCG concentration in cases and in controls were statistically highly significant $(\mathrm{p}<0.001)$. It is also found that there is positive correlation between serum $\beta$ hCG concentration with Blood pressure levels both systolic and diastolic pressure. Total Cholesterol, LDLCholesterol and Triglycerides were found to high value in cases than controls with statistically significant $(\mathrm{p}<0.01)$ differences. Pregnant women with pregnancy induced hypertension have higher level of serum $\beta$ hCG and serum lipid profile in comparison to normotensive women.
\end{abstract}

Copy.Right, IJAR, 2016. All rights reserved.

\section{Introduction:-}

Pregnancy is a physiological stress in which many changes occur in the milieu interior of the body, with more and more stress being laid on the biochemical changes, which occur in the haematopoietic system, during the normal pregnancy and becomes exaggerated in complications of pregnancy like in PIH. Hypertensive disorders are among the commonest and unpredictable medical disorders during pregnancy contributing significantly high to maternal and perinatal morbidity and mortality. It is one of the deadly triad along with hemorrhage and infections. Preeclampsia is the 3 rd leading etiology of maternal mortality and can complicate $314 \%$ of all pregnancies ${ }^{1}$.

In studies carried out in Asian countries of China, Myanmar, Thailand and Vietnam, preeclampsia was seen in $15 \%$ in Vietnam to $8.3 \%$ in China. Women over the age of 35 years and below the age of 20 years who are pregnant for 
the first time are potentially at high risk of eclampsia. Socioeconomic status and nutritional standard of a nation and the quality of antenatal care have a remarkable bearing on the incidence of this disease and maternal and perinatal $\operatorname{loss}^{2}$.

A number of biochemical and biophysical markers have been proposed as predictors for development of PIH in later pregnancy and the role of Placental hormones being one of them. Human chorionic gonadotropin (hCG) is a glycoprotein that is produced during pregnancy by the developing embryo and later by the syncytio trophoblast of the placenta mainly. Estimation of blood hCG titres are especially helpful in the diagnosis and management of trophoblastic disease and ectopic pregnancies. Other clinical conditions associated with increased secretion of $\beta$ hCG are Down's syndrome, neural tube defects, fetal aneuploidy and twin or higher pregnancies. Decreased levels are found in women at risk of carrying fetus with trisomy 18, ectopic pregnancy and blighted ovum. Besides the above diseases and chromosomal anomalies, hCG was also found to be abnormally raised in the urine and serum of pregnant women with pregnancy induced hypertension ${ }^{3}$.

Soheila Akbari et al (2009) studied to assess association between preeclampsia and serum level of $\beta$ human chorionic gonadotropin ( $\beta$ hCG) on 75 pregnant women. Subjects divided into 3 groups: Normotensive pregnancies, mild preeclampsia and severe preeclampsia. Then level of $\beta$ hCG was measured using Enzyme linked Immunosorbent Assay (ELISA) method. The mean level of $\beta$ hCG was significantly higher $(\mathrm{p}<0.001)$ in severe preeclampsia than normotensive and mild preeclamptic groups. However, there was no significant difference between normotensive and mild preeclamptic groups regarding mean level of $\beta$ hCG. They concluded that $\beta$ hCG may be a good indicator for severe preeclampsia but it is not suitable for early diagnosis of the disease ${ }^{4}$.

Dayal Meena et al (2011) did a retrospective clinical study of serum markers ( $\beta$ hCG, $\alpha$-fetoprotein and inhibin A) as predictors of preeclampsia in 50 antenatal women by ELISA technique and found that 10 women developed preeclampsia (20\%). A significant rise of mean serum $\beta$ hCG was found in those who developed preeclampsia ${ }^{\mathbf{5}}$.

Kaaja et al (1995) postulated that lipid abnormalities play a role in the pathogenesis of gestational hypertension, causing altered endothelial function and vascular damage ${ }^{6}$.

Sillman et al (1994) in the same year concluded that insulin resistance may contribute to pathogenesis of PIH. Insulin has an important role in lipid metabolism. High concentration of free fatty acids in PIH is due to their increased mobilization from adipose tissues. In case of insulin resistance, there is increased triglycerides concentration in blood as lipoprotein lipase does not metabolise triglycerides ${ }^{7}$.

The Free Fatty Acids and Triglyceride levels begin to rise 15-20 weeks of gestation before clinical parameters of preeclampsia are seen. The dramatic increase in Triglyceride results in an increase in VLDL, small changes in LDL and decreased HDL. Elevation of Free Fatty Acids and Triglyceride deposition in endothelial cells may point out oxidative stress induced by cytokines. Serum Triglyceride, Low Density Lipoprotein Cholesterol (LDL-C) was found to be significantly higher in PIH case than normal controls $\mathbf{8}^{\mathbf{2}}$.

So, keeping the above facts in mind and preeclampsia being much prevalent in our part of the country, this study was done with to evaluate the concentration of serum Beta human Chorionic Gonadotropin ( $\beta$ hCG) and Lipid Profile level and its correlation with pregnancy induced hypertension and to compare the serum $\beta$ hCG concentration and Lipid Profile level between study and control group.

\section{Materials and methods:-}

The study was carried out in the department of Biochemistry, Assam Medical College and Hospital, Dibrugarh. The study includes two group cases and controls. The cases included in the study were taken from Obstetrics and Gynaecology Department, AMCH during the period of study. The cases comprised of 50 clinically established cases of Pregnancy Induced Hypertension (PIH) in their third trimester and the control group comprised of 50 cases of normotensive pregnant patients in the third trimester.
Aims:-
1) To evaluate the concentration of serum $\beta$ hCG and lipid profile level and its correlation with pregnancy induced hypertension.
2) To compare the serum $\beta$ hCG and lipid profile level between study and control group. 


\section{Inclusion criteria:-}

Pregnant woman with systolic blood pressure of at least $140 \mathrm{mmHg}$ with a $>30 \mathrm{mmHg}$ rise and /or diastolic blood pressure at least $90 \mathrm{mmHg}$ with rise of $>15 \mathrm{mmHg}$ occurring on two or more occasions after 24weeks of gestation was included in the study.

\section{Exclusion criteria:-}

1. Woman with hypertension diagnosed before 24 weeks of gestation.

2. Woman with diabetes mellitus.

3. Multiple pregnancies

4. Ultrasound proved congenital malformation.

All the patients in the study was subjected to detail history regarding age, parity, height, pre pregnancy weight and weight at the time of blood collection. Maternal family history of preeclampsia, past obstetric history, past medical history, smoking habit, medical histories of first degree family members and physical activity during pregnancy was noted. Systemic examination with special reference to oedema, blood pressure and gestational week was carried out and routine antenatal investigation was done.

\section{Blood sampling and preparation of serum Beta hCG:-}

The venepuncture was done in the cubital fossa. About $4 \mathrm{ml}$ of blood was drawn using perfectly dry and sterile syringe. The sample is allowed to clot for thirty minutes at room temperature. Samples were centrifuged at $5000 \mathrm{rpm}$ for 10 minutes as soon as after formation of the clot. The supernatant clear serum was then pipetted out using dry piston pipettes with disposable tips. The samples were analysed on the same day. Serum Fasting Lipid profile were estimated in Semi-auto analyzer from the study sample.

Principle of the test:- The BRIA MAGII is a sandwich immune-radiometric assay for hCG. In this method, two antibodies generated against different epitopes of the hCG antigen are used. One antibody is coupled to magnetisable cellulose and the other antibody is radiolabelled with ${ }^{125} \mathrm{I}$. hCG antigen from sample or standard binds simultaneously to the anti hCG antibody coupled magnetisable cellulose as well as radio labelled anti-hCG antibody. The 'bound complex' is separated from the 'free' radiolabelled antibody using antibody coupled magnetisable cellulose particles using a magnetic rack. The radioactivity in the bound fraction is directly related to the concentration of the antigen and quantitated using gamma counter calibrated for ${ }^{125} \mathrm{I}^{\mathbf{9}}$

\section{Serum Triglyceride estimation (GPO/PAP method) ${ }^{10}$}

Principle:- Triglycerdes are hydrolysed by lipase to glycerol and free fatty acids. Glycerol is phosphorylated by ATP in the presence of glycerol kinase to glycerol 3-phosphate, which is oxidized by the enzyme glycerol 3phosphate oxidase (GPO) producing hydrogen peroxide. Hydrogen peroxide so formed reacts with phenolic compound and 4-aminoantipyrine to give a red coloured quinoneimine complex which is proportional to the amount of Triglyceride present in the sample.

\section{Serum Cholesterol estimation: (CHOD/PAP method) ${ }^{11}$}

Principle:- Cholesterol esterase (CHE) hydrolyses cholesterol ester to free cholesterol. Free cholesterol is oxidized to hydrogen peroxide. Hydrogen peroxide formed reacts with 4amino antipyrine and phenol in the presence of Peroxidase (POD) to produce red coloured quinoneimine dye complex. Intensity of the colour formed is directly proportional to the amount of cholesterol present in the sample.

HDL cholesterol estimation (PEG/ CHOD/PAP method) ${ }^{12}$

Principle:- When the serum is reacted with the Polyethylene Glycol contained in the precipitating reagent, all the VLDL and LDL are precipitated. The HDL remains in the supernatant and is then assayed as a sample for cholesterol using the Cholesterol (CHOD/PAP) reagent.

\section{LDL Cholesterol estimation:-}

LDL Cholesterol is calculated by using Friedwald's formula.

LDL Cholesterol in $\mathrm{mg} / \mathrm{dl}=$ Total cholesterol/5 $-($ HDL-Cholesterol $)$

\section{Estimation of VLDL:-}


VLDL is the primary triglyceride carrying form in the fasting state; its concentration can be approximated by dividing the amount of plasma triglyceride by $\mathbf{5}$.

Statistical analysis:- The present study is a randomised case control study and results were expressed as Arithmetic Mean \pm Standard Deviations (SD) and analysed by unpaired Student's t-test on continuous measurements and results on categorical measurements were presented in Number (\%). Pearson coefficient of correlation (r) was used to find out the correlation between Blood pressure and the serum $\beta$ hCG concentration.

P-Value: $p<0.05$ is considered significant, $p<0.01$ is considered highly significant, $p<0.001$ is considered very highly significant, $p>0.05$ is considered not significant.

Coefficient of Correlation:- To see the correlation between two variables coefficient of correlation $(r)$ was applied. The correlation coefficient ' $r$ ' tends to lie between -1.0 and +1.0 . If $r$ is near +1 , it indicates a strong positive correlation i.e. when one variable increases, the other also increases. A value in minus side indicates inverse correlation, i.e. when one variable increases, the other decreases. If $r=0$, it indicates no correlation.

The Mean \pm S.D, Median and Range of the $\beta$ hCG values obtained for normotensive group of patients was calculated. The serum $\beta$ hCG values obtained for the hypertensive group of patients were compared with the median level of serum $\beta$ hCG in the normotensive group the outcome of pregnancy noted. The results were expressed as Multiple of Median (MoM) for normal pregnancy.

\section{Results:-}

In the present study it is found that the mean serum $\beta$ hCG concentration in cases was $42.94 \pm 18.91$ ranging from 15 $78 \mathrm{IU} / \mathrm{mL}$ and in controls was $24.18 \pm 11.34$ ranging from $10-49 \mathrm{IU} / \mathrm{mL}$ and it was statistically very highly significant ( $\mathrm{p}<0.001$ ). Thus, the serum $\beta$ hCG concentration increases in PIH patients.

Table 1:- Age wise distribution of mean $\beta$ hCG concentrations of PIH patients and normal pregnant women.

\begin{tabular}{|c|c|c|c|c|}
\hline \multirow{2}{*}{$\begin{array}{c}\text { Age Group } \\
\text { (years) }\end{array}$} & \multicolumn{3}{|c|}{$\beta$-hCG $($ IU/mL) } \\
\cline { 2 - 5 } & PIH patients & Normal pregnant women \\
\cline { 2 - 5 } & Mean \pm SD & Range & Mean \pm SD \\
\hline $16-20$ & $18-78$ & $45.2 \pm 21.82$ & $11-46$ & $22.44 \pm 13.49$ \\
\hline $21-25$ & $\mathbf{2 1 - 7 6}$ & $42.21 \pm 18.73$ & $10-42$ & $21.65 \pm 9.45$ \\
\hline $26-30$ & $15-65$ & $36.07 \pm 16.00$ & $10-49$ & $28.21 \pm 12.82$ \\
\hline $31-35$ & $16-76$ & $49.92 \pm 19.18$ & $10-43$ & $24.4 \pm 10.08$ \\
\hline Total & $15-78$ & $42.94 \pm 18.91$ & $10-49$ & $24.18 \pm 11.34$ \\
\hline
\end{tabular}

It is also found that there is positive correlation between serum $\beta$ hCG concentration with Blood pressure levels both systolic and diastolic pressure with Pearson Correlation co-efficient " $r$ " values 0.64 for systolic pressure and 0.62 for diastolic pressure.

Table 2:- Pearson coefficient of correlation and p-value of blood pressure with serum $\beta$-hCG concentration of $\mathrm{PIH}$ patients and normal pregnant women.

\begin{tabular}{|c|c|c|c|c|}
\hline \multirow{2}{*}{$\begin{array}{c}\text { BLOOD } \\
\text { PRESSURE }\end{array}$} & \multicolumn{3}{|c|}{ PIH patients } & \multicolumn{2}{c|}{ Normal pregnant women } \\
\cline { 2 - 5 } & r value & p value & r value & p value \\
\hline SYSTOLIC & $\mathbf{0 . 6 4}$ & $<0.0001$ & 0.06 & 0.68 \\
\hline DIASTOLIC & $\mathbf{0 . 6 2}$ & $<0.0001$ & 0.17 & 0.24 \\
\hline
\end{tabular}

The mean serum levels of Total Cholesterol in hypertensive are (191.65 $\pm \mathbf{3 7 . 2 1}) \mathrm{mg} / \mathrm{dl}$ and in normotensive is $\mathbf{( 1 4 6 . 8 4} \pm \mathbf{2 5 . 2 1}) \mathrm{mg} / \mathrm{dl}$. $\mathrm{t}$ - test revealed very highly significant differences $(\mathbf{p}<\mathbf{0 . 0 1})$ in Total Cholesterol values in between hypertensive and normotensive groups. (Table-3)

Table 3: Comparison of mean Serum Lipid profile in hypertensive and normotensive study participants.

\begin{tabular}{|l|c|c|c|c|c|}
\hline \multirow{2}{*}{ Parameters } & \multicolumn{4}{l|}{ Hypertensive (mg/dl) } & \multicolumn{2}{l|}{ Normotensive (mg/dl) } & \\
\cline { 2 - 6 } & Mean & S.D & Mean & S.D & \\
\hline Total Cholesterol & $\mathbf{1 9 1 . 6 5}$ & $\mathbf{3 7 . 2 1}$ & $\mathbf{1 4 6 . 8 4}$ & $\mathbf{2 5 . 2 1}$ & $<0.01$ \\
\hline Triglyceride & $\mathbf{2 0 0 . 6 0}$ & $\mathbf{4 2 . 5 7}$ & $\mathbf{1 6 2 . 8 4}$ & $\mathbf{2 1 . 9 2}$ & $<0.01$ \\
\hline HDL Cholesterol & 39.47 & $\mathbf{6 . 8 9}$ & $\mathbf{3 9 . 8 8}$ & $\mathbf{5 . 4 8}$ & $\mathbf{0 . 7 4}$ \\
\hline
\end{tabular}




\begin{tabular}{|l|c|c|c|c|c|}
\hline LDL Cholesterol & $\mathbf{1 1 2 . 0 8}$ & $\mathbf{3 1 . 4 9}$ & $\mathbf{7 4 . 0 9}$ & $\mathbf{1 9 . 9 8}$ & $<0.01$ \\
\hline VLDL Cholesterol & $\mathbf{4 0 . 1 1}$ & $\mathbf{8 . 5 1}$ & $\mathbf{3 2 . 5 7}$ & $\mathbf{4 . 3 8}$ & $<0.01$ \\
\hline
\end{tabular}

The mean serum levels of TAG in hypertensive are $\mathbf{( 2 0 0 . 6 0 \pm 4 2 . 5 7 ) ~} \mathrm{mg} / \mathrm{dl}$ and in normotensive is (162.84 \pm 21.92$)$ $\mathrm{mg} / \mathrm{dl}$. $\mathrm{t}$ - test revealed very highly significant differences $(\mathbf{p}<\mathbf{0 . 0 1})$ in TAG values in between hypertensive and normotensive groups. (Table-3)

The mean serum levels of HDL Cholesterol in hypertensive are (39.47 $\pm \mathbf{6 . 8 9}) \mathrm{mg} / \mathrm{dl}$ and in normotensive is $\mathbf{( 3 9 . 8 8} \pm \mathbf{5 . 4 8}) \mathrm{mg} / \mathrm{dl}$. $\mathrm{t}$ - test revealed not significant differences $(\mathbf{p}<\mathbf{0 . 7 4})$ in HDL Cholesterol values in between hypertensive and normotensive groups. (Table-3)

The mean serum levels of LDL Cholesterol in hypertensive are (112.08+31.49) $\mathrm{mg} / \mathrm{dl}$ and in normotensive is $\mathbf{( 7 4 . 0 9 \pm 1 9 . 9 8 )} \mathrm{mg} / \mathrm{dl}$. $\mathrm{t}$ - test revealed very highly significant differences $(\mathbf{p}<\mathbf{0 . 0 1})$ in LDL Cholesterol values in between hypertensive and normotensive groups. (Table-3)

The mean serum levels of VLDL Cholesterol in hypertensive are (40.11 $\mathbf{8 . 5 1}) \mathrm{mg} / \mathrm{dl}$ and in normotensive is $\mathbf{( 3 2 . 5 7 \pm 4 . 3 8 )} \mathrm{mg} / \mathrm{dl}$. $\mathrm{t}$ - test revealed very highly significant differences $(\mathbf{p}<\mathbf{0 . 0 1})$ in VLDL Cholesterol values in between hypertensive and normotensive groups. (Table-3)

\begin{tabular}{|l|c|c|c|c|}
\hline \multirow{2}{*}{ Table 4:- Correlation } & \multicolumn{2}{c|}{ Blood Pressure (BP) } \\
\cline { 2 - 5 } & $\mathbf{4}$ Systolic BP & D & Diastolic BP \\
\cline { 2 - 5 } & $\mathbf{r}$ & $\mathbf{p}$ & $\mathbf{0 . 0 2}$ & $\mathbf{0 . 8 9}$ \\
\hline Cholesterol & $\mathbf{0 . 1 3}$ & $\mathbf{0 . 3 7}$ & $\mathbf{0 . 1 0}$ & $\mathbf{0 . 4 9}$ \\
\hline Triglyceride & $\mathbf{0 . 0 2}$ & $\mathbf{0 . 3 7}$ & $\mathbf{0 . 0 4}$ & $\mathbf{0 . 7 8}$ \\
\hline HDL & $\mathbf{0 . 1 3}$ & $\mathbf{0 . 3 7}$ & $\mathbf{0 . 0 1}$ & $\mathbf{0 . 9 5}$ \\
\hline LDL & $\mathbf{0 . 1 3}$ & $\mathbf{0 . 8 9}$ & $\mathbf{0 . 1 0}$ & $\mathbf{0 . 4 9}$ \\
\hline VLDL & $\mathbf{0 . 0 2}$ & & & \\
\hline
\end{tabular}

Table 4 shows that there is very weak positive correlation between blood pressure and lipid profile of pregnancy induced hypertension patients and it is not significant statistically.

\section{Discussion:-}

In the 50 hypertensive cases which were studied, the maximum number of 16 cases (32\%) belonged to the 16-20 years age group and 8 (16\%) were from the age group of 20-25 years. After combining both the groups, we get the highest number of 26 cases (48\%) were found 16-25 years age group. Similar findings were also found by Farnoosh et al (2012) ${ }^{\mathbf{1 3}}$ who recorded maximum incidence in age group 15-25 age group. In the age group of $\leq 20$ years there were 16 hypertensive cases which constitute $32 \%$ of total number of participants. In $31-35$ years age group $32 \%$ were hypertensive. This can be attributed to the fact that increased episodes of preeclampsia occurs in extremes of maternal age.

In the present study there were $32(64 \%)$ who were primigravidas and $18(32 \%)$ were multigravidas in the hypertensive study group. Surraya H et al $(2010)^{\mathbf{1 4}}$, D.S. Seidman et al (1990) ${ }^{\mathbf{1 5}}$ also found in their study that hypertensive disorders of pregnancy affects mainly the first pregnancy.

Analysis of serum $\beta \mathrm{hCG}$ in the study participants the mean serum $\beta \mathrm{hCG}$ values for the patients in PIH (42.94 $\mathrm{IU} / \mathrm{mL})$ was significantly higher $(\mathrm{P}<0.0001)$ than found in the normotensive group $(24.18 \mathrm{IU} / \mathrm{mL})$. Pearson's coefficient between blood pressure and serum $\beta$ hCG of hypertensive group shows positive correlation and are statistically very highly significant. Similar results were observed by, Basirat Z et al (2006) ${ }^{\mathbf{1 6}}$, Yousefnejad et al $(2008)^{\mathbf{1 7}}$ and Vidyabati RK et al (2010) ${ }^{\mathbf{1 8}}$ Gurmandeep K et al (2012) ${ }^{\mathbf{1 9}}$

Analysis of total cholesterol in the study participants, showed that serum total cholesterol was found significant $(\mathrm{p}<0.01)$ in hypertensive study participants $(191.65 \pm 37.21 \mathrm{mg} / \mathrm{dl})$ than in normotensive $(146.84 \pm 25.21 \mathrm{mg} / \mathrm{dl})$ pregnant participants. M. T. M. Anceschi et al., (2005) also found that serum cholesterol levels were higher in normotensive and gradually increased more in preeclampsia ${ }^{20}$. Total Cholesterol levels did not increase during normal mid trimester pregnancy, but cholesterol levels were significantly higher in cases with severe hypertension ${ }^{\mathbf{2 1}}$. 
Serum Triacylglycerol in the hypertensive study participants was found to be $(200.60 \pm 42.57 \mathrm{mg} / \mathrm{dl})$ and which showed statistically significant difference $(\mathrm{p}<0.01)$ in the normotensives $(162.84 \pm 21.92 \mathrm{mg} / \mathrm{dl})$ participants. The VLDL Cholesterol was found to be significant difference $(\mathrm{p}<0.01)$ between hypertensive cases $(40.11 \pm 8.51 \mathrm{mg} / \mathrm{dl})$ than normotensive cases $(32.57 \pm 4.38 \mathrm{mg} / \mathrm{dl})$.

This finding was consistent with study Suchanda et al,(2008) ${ }^{\mathbf{2 2}}$. He found that higher triglycerides level in hypertensive patients than normotensive controls. $(233.57 \pm 34.6$ vs $86.7 \pm 10.8)(\mathrm{p}<0.01)$

Analysis of HDL cholesterol in the study participants, showed that serum HDL Cholesterol was not significant (p $0.74)$ in hypertensive study participants $(39.47 \pm 6.89 \mathrm{mg} / \mathrm{dl})$ than in the normotensives $(39.88 \pm 5.48 \mathrm{mg} / \mathrm{dl})$. Kashinakunti et al,(2002) ${ }^{\mathbf{2 3}}$ also found in his study that there was no significant differences between pregnancy with $\mathrm{PIH}$ and Normotensive pregnant women in their third trimester of pregnancy $(43.2 \pm 8.71 \mathrm{mg} / \mathrm{dl} \mathrm{vs} 41.43 \pm 6.88 \mathrm{mg} / \mathrm{dl}$ ) .

Analysis of LDL cholesterol in the study participants, showed that serum LDL Cholesterol was significant difference $(\mathrm{p}<0.01)$ in hypertensive study participants $(112.08 \pm 31.49 \mathrm{mg} / \mathrm{dl})$ than in the normotensives participants (79.09 $\pm 19.98 \mathrm{mg} / \mathrm{dl})$. Shalini M. et al., $(2011)^{\mathbf{2 4}}$ found higher LDL Cholesterol levels in hypertensive patients than normotensive controls $(135.71 \pm 32.20$ vs $115.56 \pm 12.02 \mathrm{mg} / \mathrm{dl}, \mathrm{P}<0.012)$.

So it can be stated that the elevation of blood pressure in hypertension of pregnancy was influenced by the lipid profile and thus the lipid profile of a hypertensive pregnant women can with all probabilities be used as a biochemical marker of the disease. .

Pearson's coefficient between blood pressure and Lipid Profile of Hypertensive group shows weakly positive correlation and are statistically not significant.

\section{Conclusion:-}

From the present study it can be concluded that pregnant women with pregnancy induced hypertension have higher level of serum $\beta$ hCG in comparison to normotensive women. It is also observed that higher value of lipid profile parameters in comparison to normotensive women. Serial estimation of serum $\beta$ hCG and Lipid Profile can very well be used as biochemical markers of the disease and also can be used in better management of established cases of eclampsia or preeclampsia.

The metabolic disorder that occurs in pregnancies with pregnancy induced hypertension may be important and may be a predictor of future systemic diseases in these women. Therefore more studies are warranted into the implications of these predictors of hypertension during pregnancy.

\section{References:-}

1. Irminger FI, Jastrow N, Irion O. Preeclampsia: A danger growing in disguise. Int J Biochem Cell Biol. 2008 April; 40(10):1979-83.

2. Carmen D, Carla A. Global burden of hypertensive disorders of pregnancy in the year 2000. Evidence and Information for Policy. World Health Organization. Geneva; 2003 July.

3. FG Cunningham, JC Hauth, KJ Leveno, LG III, SL Bloom, KD Wenstrom. Williams Obstetrics. $22^{\text {nd }}$ ed. New Delhi: McGraw-Hill; 2005. p. 39-91

4. Soheila A, Sepideh V, Mojtatba K. A Study of $\beta$ hCG in preeclamptic and normotensive pregnant women. Research J of Biological Sciences. 2009; 4:468-71.

5. Dayal M, Gupta P, Verma M, Ghosh UK, Bhargava A. Role of Second Trimester Maternal Serum markers as Predictors of preeclampsia. The J of Obstet and Gynecol of India; 2011 June: 38-41.

6. Kaaja R, Tikkanen MJ, Viinikka L, Ylikorkala O. Serum lipoproteins, insulin, and urinary prostanoid metabolites in normal and hypertensive pregnant women. Br J of Obstet Gynecol. Mar.1995; 85(3):353-56

7. Silliman K, Shore V, Forte TM. Hypertriglyceridemia during late pregnancy is associated with the formation of small dense low density lipoproteins and the presence of large buoyant high density lipoproteins. Metabolism 1994 Aug; 43(8):1035-41. 
8. Sattar N, Gaw A, Packard CJ. Potential pathogenic roles of aberrant lipoprotein and fatty acid metabolism in preeclampsia. Br J of Obstet. Gynecol. 1996; 103: 613-21

9. Board of radiation and isotope technology (BRIT): www.britatom.gov.in. Navi Mumbai-400705, India.

10. Triglycerides kit (GPO / PAP Method), For the Determination of Triglycerides in Serum or Plasma (For in vitro diagnostic use only).

11. Cholesterol kit (CHOD-PAP Method) For the Determination of Cholesterol in Serum or Plasma (For invitro diagnostic use only)

12. HDL Cholesterol kit (PEG / CHOD-PAP Method) For the Determination of HDL Cholesterol in Serum or Plasma (For invitro diagnostic use only)

13. Farnoosh K, Ameneh S, Tahereh B. Survey of Correlation between Preeclampsia and Season \& Some of its Risk Factor in Pregnant women. J Women's Health care. 2012; 1:3.

14. Surraya H, Syed M, Ashhad H. Eclampsia and its association with external factors; J Ayub Med Coll Abbottabad. 2010; 22(3):110-12.

15. DS Seidman, A Samueloff, S Moryosef, JG Schenker. The effect of maternal age and socio-economical background on neonatal outcome. Int J of Gynecol \& Obstet. 1990 September; 33(1):7-12.

16. Zahra B, Shanaz B, Mahmood H. Serum $\beta$ hCG levels and preeclampsia. Saudi Med J. $2006 ; 27$ (7):1001-7

17. K Yousefnejad, N Moslemizadeh. Serum Beta hCG Levels in Diagnosis and Management of Preeclampsia. J of Medical Sciences. 2008; 8:722-27.

18. Vidyabati RK, Hijam D, Singh NK, Singh WG. Serum $\beta$ hCG and lipid profile in early second trimester as predictors of pregnancy induced hypertension. J Obstet Gynecol of India. 2010; 60(1): 44-50.

19. Gurmandeep K, Vimla J, Seema M, Sunita H. Prediction PIH by Metarnal Serum $\beta$ hCG level in second trimester of pregnancy. J of Obstet and Gynecol of India. 2012 February; 62(1): 32-34.

20. MTM Anceschi, G Coata, EV Cosmi, A Gaiti, G Frovarelli, GC Di Renzo. Erythrocyte membrane composition in pregnancy induced hypertension: evidence for an altered lipid profile. Br J Obstet Gyanecol. 2005; 99(6): 503-7.

21. Rohita B, Keerti M, Deepak S, Manisha S. The Relationship between Oxidative Stress and Atherogenic Index in Preeclampsia. Sch J App Med Sci. 2014; 2(6D):3092-96

22. S Sahu, R Ahraham, R Vedavalli, M Daniel. Ind J Physiol Pharmacol. 2009; 53(4):365-69.

23. Kashinakunti SV, Sunitha H, Gurupadappa K, Manjula R. Lipid Profile In Preeclampsia - A Case Control Study. J of Clinical and Diagnostic Research. 2010 August; 4:2748-51.

24. Shalini M, Rashmi R, Nitin M, Sharma A. Study of serum lipid profile and magnesium in normal pregnancy and in pre-eclampsia: A case control study. Asian J Biochem. 2011;6: 228-39. 